\title{
RETRACTED ARTICLE: Functionalized benzyls as selective K-OR agonists
}

\author{
Bojidarka Ivanova $\cdot$ Michael Spiteller
}

Received: 30 January 2013/Accepted: 25 April 2014/Published online: 1 June 2014

(C) Springer Science+Business Media New York 2015

The article has been retracted by the co-author due to the author's findings of inconsistencies between the reported compounds and the NMR experimental data.

B. Ivanova $(\varangle) \cdot$ M. Spiteller

Lehrstuhl für Analytische Chemie, Institut für Umweltforschung, Fakultät für Chemie, Universität Dortmund, Otto-Hahn-Straße 6, 44227 Dortmund, North Rheine-Westphalia, Germany

e-mail: B.Ivanova@infu.uni-dortmund.de; B.Ivanova@web.de 